\title{
Comment on "Addressing the importance of microplastic particles as vectors for long-range transport of chemical contaminants: perspective in relation to prioritizing research and regulatory actions"\#¥
}

\author{
Juliane Glüge, ${ }^{1,2}$ Narain M. Ashta, ${ }^{1}$ Dorte Herzke ${ }^{3}$, Laurent Lebreton ${ }^{4,5}$ \& Martin Scheringer ${ }^{1,6^{*}}$ \\ ${ }^{1}$ Institute of Biogeochemistry and Pollutant Dynamics, ETH Zürich, 8092 Zürich, Switzerland \\ ${ }^{2}$ Department of Cell Toxicology, UFZ Leipzig-Halle, 04318 Leipzig, Germany \\ ${ }^{3}$ Norwegian Institute for Air Research (NILU), N-9296 Troms $\varnothing$, Norway; Institute for Arctic and Marine \\ Biology, UiT The Arctic University of Norway, N-9037 Troms $\varnothing$, Norway \\ ${ }^{4}$ The Ocean Cleanup, $3014 \mathrm{JH}$ Rotterdam, The Netherlands \\ ${ }^{5}$ The Modelling House, 3225 Raglan, New Zealand \\ ${ }^{6}$ RECETOX, Masaryk University, 62500 Brno, Czech Republic \\ *scheringer@usys.ethz.ch
}

\begin{abstract}
Important clarifications regarding the long-range environmental transport of chemical additives contained in floating plastic debris are presented.
\end{abstract}

The Perspective article by Gouin ${ }^{1}$ summarizes various aspects of the environmental long-range transport of plastic particles and non-polymeric chemicals, and also discusses the present knowledge about, and uncertainties associated with, the transport of microplastics (MPs) and additives contained in MPs. However, the article contains many misinterpretations and inaccuracies that lead to incorrect conclusions. We argue therefore that this Perspective should be seen as an expression of the author's personal point of view, but should not be used as a source of information in discussions about the long-range environmental transport (LRET) of chemical plastic additives. The shortcomings of the Perspective are:

\section{1) Omission of meso- and macroplastics}

The Perspective focuses mainly on MPs and overlooks that it is not only MPs that can carry chemicals. It is mentioned that degradation and fragmentation of larger plastic items is an important source of MPs, but the transport and fate of particles larger than $5 \mathrm{~mm}$ is not considered in the Perspective. However, more than three quarters of the plastic debris (by mass) in the Great Pacific Garbage Patch is larger than $5 \mathrm{~cm}^{2}{ }^{2}$ Meso- and macroplastics are considerable vectors for chemical transport, and reducing the discussion to MPs distorts the overall picture. Even more importantly, is has been shown that MPs smaller than $1 \mathrm{~mm}$ may not be easily available for oceanic long-range transport. ${ }^{3-7}$ This fact is ignored in the Perspective and results of studies that are cited are not related to the LRET of chemical contaminants because they focus primarily on particles smaller than $1 \mathrm{~mm}$ (e.g. Dibke et al. $(2021)^{8}$ and Schernewski et al. $\left.(2020)^{9}\right)$.

\# Gouin, T. (2021) Microplastics and Nanoplastics 1 (1), 14. https://doi.org/10.1186/s43591-02100016-w.

¥ Accepted for publication in Microplastics and Nanoplastics 


\section{2) Inappropriate consideration of adsorbed chemicals}

One of the main statements in the Perspective is "... I perceive that the weight-of-evidence supports exposure to POPs via the LRET of MPs to be minimal relative to other transport pathways, see for instance [24-27]." While the statement as such is not incorrect, citations 24 to 27 are Zarfl et al. (2010), ${ }^{10}$ Bakir et al. (2016), Gouin et al. (2011), ${ }^{11}$ and Koelmans et al. (2016), ${ }^{12}$ all of which address chemicals that are adsorbed to plastics. Here the author made a statement about adsorbed chemicals, creating the impression that it would also be relevant for chemicals used as additives in plastics. A key difference is that chemical additives are present in plastic in concentrations higher by several orders of magnitude than concentrations of adsorbed contaminants. ${ }^{13}$ Conclusions, especially on the mass balance from studies that only look at adsorbed chemicals, are therefore not relevant and valid for chemical additives. This has already been pointed out by Andrade et al. (2021), but is not mentioned in the Perspective. Andrade et al. have shown "that approximately 8,100-18,900 t of various organic additives are transported with buoyant plastic matrices globally with a significant portion also transported to the Arctic. For many of these chemicals, long-range transport (LRT) by plastic as a carrier is their only means of travelling over long distances without degrading, resulting in plastic debris enabling the LRT of chemicals which otherwise would not reach polar environments with unknown consequences."

\section{3) Particulate organic matter is not a good analogue to plastic to learn about LRET}

It is mentioned in the Perspective that particulate organic matter (POM) has a density and particle size that is similar to that of MPs and that "hydrological factors that influence the fate of POM in these systems, has the potential to influence the fate of the MPs in a similar manner." This might be correct for shorter time periods. However, POM is biodegradable and will therefore not serve as a vector for the LRET of chemicals. ${ }^{14}$

\section{4) View on leaching of plastic additives too narrow}

The first part of the section "Does plastic represent a source of exposure to plastic-additive chemicals" discusses the diffusion and evaporation of plastic additives out of plastic into air. In comparison to these very detailed explanations, leaching of plastic additives into water or exposed organisms is not described at all (water) or only very briefly (exposed organisms). Especially for very hydrophobic substances, however, leaching into fat and oil is very relevant and clearly more important than diffusion into air. It is therefore necessary to also consider leaching in the gastrointestinal tract of exposed organisms. ${ }^{15,16}$ The cases presented in the Perspective, which are intended to show that ingestion of MPs does not represent a significant source of exposure relative to other exposure pathways, are misleading as they represent substances (nonylphenol and bisphenol A) that are metabolized in fish and probably also in other organisms. ${ }^{17,18}$ The high concentrations found for bisphenol A and nonylphenol therefore do not result from bioaccumulation but from high exposure levels. This is different for substances such as UV-328 that are only slowly metabolized. ${ }^{19,20}$ Experimental results show here that leaching into digestive fluids of seabirds is a relevant exposure pathway. ${ }^{15,16}$

\section{5) Inappropriate and unfounded criticism of the study by Andrade et al. (2021)}

The Perspective attempts to debase the article by Andrade et al. $(2021)^{21}$ with incorrect statements. In the Perspective, it is stated that Andrade et al. (2021) used an average weight fraction of $5 \%$ for the total of chemical additives associated with plastic debris. However, this is not correct. Andrade et al. $(2021)^{21}$ used a range of $3 \%$ to $7 \%$. It is also stated in the perceptive that the weight fraction adopted by Andrade et al. $(2021)^{21}$ is likely skewed due to the higher 
weight fractions of additives associated with polyvinylchloride (PVC). However, Andrade et al. $(2021)^{21}$ explicitly state that there are differences across polymers types and uses and that the range of $3 \%$ to $7 \%$ "does not cover brominated flame retardants, which are used at around $20 \%$ (e.g. BDE-209 in PE [138]), nor plasticisers, which are used in PVC at 33\% on average [138]." Gouin himself shows in his Table 1 percentages of additives used across polymer types, easily proving the numbers stated by Andrade et al. (2021) to be rather on the low end of possible total additive concentrations found. There is therefore no reason to discredit the statements and numbers of Andrade et al. (2021), ${ }^{21}$ as done in the Perspective with the sentence "Caution should thus be used not to overinterpret the significance of the estimates reported by Andrade et al. [133]."

\section{6) Fishing net debris does not necessarily have to be from a local source}

It is also argued in the Perspective that fishing-and shipping-related materials might be the main source of plastic debris and MP in both surface waters and sediment and that "shipping and/or fishing activity off the coast of remote islands that result in the release and subsequent beaching of plastic debris on their beaches, would, ... reflect a local source." Here, the general assumption that fishing and shipping related materials are an important source of plastic debris in the offshore ocean seems to be correct. Lebreton et al. (2018) showed that $52 \%$ of the total floating plastic mass in the Great Pacific Garbage Patch is composed of fishing nets, ropes and plastic lines and $47 \%$ of hard plastics, sheets and films. However, a key point in this context is that fishing debris does not automatically have to be from local sources. Here, we modeled the travel distance and travel time of plastic debris stranding on the beaches of Marion Island and Gough Island, two remote islands located in the Sub-Antarctic Indian Ocean and Southern Atlantic Ocean, respectively, where high concentrations of chemical additives have been detected in the preen gland oil of birds. ${ }^{22}$ Details on the applied ocean circulation model, the two scenarios investigated and the results are provided in the Appendix. In brief, the model shows that plastic debris from river sources is very unlikely to reach Marion Island. Plastic debris from fishing sources reaching Marion Island originated mainly from areas south of the American continent and fishing grounds near Antarctica. The mean direct distance from sources is $5500 \mathrm{~km}$ (range 3250 to $7250 \mathrm{~km}$ ). Less than $7 \%$ of the plastic came from local fishing grounds, west of the island with distances to sources less than $1000 \mathrm{~km}$. For Gough Island, the model shows that more than $99 \%$ of the debris from river sources mostly originated from Brazilian rivers, located more than $3000 \mathrm{~km}$ away. Plastic debris from fishing sources originated mainly from fishing grounds off the coast of Argentina and travelled on average $4000 \mathrm{~km}$ (95 percentile 3000 to $5000 \mathrm{~km}$ ). These results clearly show that fishing debris does not necessarily have to be from a local source and can undergo LRT. Consequently, plastic-associated chemicals can undergo LRT as well.

7) The fact that much of the plastic debris from land-based sources remains near the coast does not mean that plastic debris cannot undergo LRET

It is also argued in the Perspective that MPs tend to accumulate in the vicinity of their emission sources, based for example on data from Turrell (2020), "3 "who report results of a model describing the sources of marine plastic litter and MPs to the Scottish Atlantic and North Sea Coast, which are dominated from sources related to littering along the Scottish coast." The statement is in line with modelling results from Onink et al. (2021), ${ }^{24}$ who showed that at least $77 \%$ of the buoyant marine plastic debris remain within $10 \mathrm{~km}$ of the model coastline and that only a small fraction escapes to the open ocean. However, there are two important points 
here: (i) Onink et al. (2021) $)^{24}$ stated that the local fraction of beached buoyant marine plastic debris is relatively low for islands and (ii) even if much of the plastic remains near the coast, there is still a proportion that is transported into the open ocean and eventually over long distances. The results of Turrell $(2020)^{23}$ and Onink et al. (2021) ${ }^{24}$ therefore do not point against the potential of plastic debris to undergo long-range environmental transport. There is additional evidence from monitoring studies that plastic debris undergoes LRET. The International Pellet Watch has shown that plastic pellets, although they derived from landbased sources, occur on beaches of remote and desert islands such as Macquarie Island and Henderson Island. ${ }^{25}$

8) The call for better mechanistically-based models is justified, but the existing models describe the transport at least for large fragments in an acceptable way

At several points in the Perspective, it is emphasised that not enough is known about the fate and transport of MPs and chemical additives in MPs to decide whether or not MPs and chemical additives in MPs are able to undergo LRET. It is therefore suggested that "the development and application of mechanistically-based models and the acquisition of reliable and consistent monitoring data are urgently needed to better identify and characterize the sources, sinks and environmental fate processes of MPs." We agree that better mechanistic models are needed to understand the fate of MPs. Considerations of the size, shape and surface-area to volume ratio are very important to understand the presence of small particles at the surface of the ocean. ${ }^{26,27}$ Particularly, the surface-area to volume ratio determines how a particle's floatability is impacted by biofouling from organisms or aggregation with natural colloids. ${ }^{28}$ These processes are rarely considered in $2 \mathrm{D}$ transport models where every particle moves with the surface current. This is, however, not so much of a problem when large floating plastics are modeled as they maintain very high rising velocities. Large positively buoyant plastic fragments, with their smaller surface-area to volume ratios, are less prone to sinking than MPs, so that studying their dispersal over a long period of time as we do here, around one year of travel at least, is acceptable. There are still many ways to improve the models also for large plastic debris e.g. by including an interface between wind and current drag, including stokes drift, beaching and others, but the models that exist are able to describe the transport of large plastic fragments, including their LRET potential, in a sufficient way. For example, the modeled accumulation zones are located in the areas where high plastic concentrations have been found empirically. ${ }^{29}$

\section{9) Perspective calls for points that have already been investigated}

Finally, we would like to point out that the Perspective often calls for points that have already been investigated. For example, it is stated "If we consider a simplistic model, whereby the relative differences in density between PVC and PE are used as parameters that influence mobility, with the density of PVC > PE, then the relative importance of PVC to act as a LRET vector of PACs will be minimal, assuming that the greater density of PVC limits mobility and potential exposure to locations near emission sources. For plastic additive chemicals that may be associated with $\mathrm{PE}$, on the other hand, and for which greater mobility can be assumed based on the simplistic model applied here, we may wish to further consider the influence of kinetic processes, such as leaching rates, which are likely to increase as particle size decreases or, alternatively, as surface area increases." However, Andrade et al. (2021) have looked exactly into this point and concluded "Highest leaching rates are therefore expected for small PE fragments. According to the equations from Endo et al. [26], the desorption half-life from PE 
for substances with a log $\mathrm{K}_{\mathrm{ow}}$ between 5.5 and 7 will be between 1 and 38 years, assuming medium-turbulent water (aqueous boundary layer $100 \mu \mathrm{m}$ ). Phthalates have been shown to leach from plastic materials; with $80-120 \mathrm{ng} \mathrm{g}^{-1}$ plastic over a period of 90 days, only a small share of their overall content (1-5 weight percent) is released in the first 3 months of exposure [91]. This shows that leaching is a relevant process but also that considerable fractions of the additives remain available for long-range transport with the plastic matrix." Thus, the Perspective often asks for more data or insights but dismisses available information.

All of the above points detract from the value of the Perspective as a reliable source, as many of the conclusions are based on inaccurate assumptions and cherry-picking of available information. Therefore, we think that the Perspective should not be used in discussions of the plastic-driven LRET of chemical additives.

\section{Availability of data and material}

Not applicable

\section{Competing interests}

The authors declare that they have no competing interests.

\section{Funding}

No funding was received for this work.

\section{Authors' contributions}

All authors contributed to the writing of the manuscript.

\section{Acknowledgements}

Not applicable

\section{References}

(1) Gouin, T. Addressing the Importance of Microplastic Particles as Vectors for Long-Range Transport of Chemical Contaminants: Perspective in Relation to Prioritizing Research and Regulatory Actions. Microplastics and Nanoplastics 2021, 1 (1), 14. https://doi.org/10.1186/s43591-021-00016-w.

(2) Lebreton, L.; Slat, B.; Ferrari, F.; Sainte-Rose, B.; Aitken, J.; Marthouse, R.; Hajbane, S.; Cunsolo, S.; Schwarz, A.; Levivier, A.; Noble, K.; Debeljak, P.; Maral, H.; Schoeneich-Argent, R.; Brambini, R.; Reisser, J. Evidence That the Great Pacific Garbage Patch Is Rapidly Accumulating Plastic. Sci. Rep. 2018, 8 (1), 1-15. https://doi.org/10.1038/s41598-018-22939w.

(3) Cózar, A.; Echevarría, F.; González-Gordillo, J. I.; Irigoien, X.; Úbeda, B.; Hernández-León, S.; Palma, Á. T.; Navarro, S.; García-de-Lomas, J.; Ruiz, A.; Fernández-de-Puelles, M. L.; Duarte, C. M. Plastic Debris in the Open Ocean. Proc. Natl. Acad. Sci. 2014, 111 (28), 10239-10244. https://doi.org/10.1073/PNAS.1314705111.

(4) Isobe, A.; Uchida, K.; Tokai, T.; Iwasaki, S. East Asian Seas: A Hot Spot of Pelagic 
Microplastics. Mar. Pollut. Bull. 2015, 101 (2), 618-623.

https://doi.org/10.1016/j.marpolbul.2015.10.042.

(5) Lobelle, D.; Kooi, M.; Koelmans, A. A.; Laufkötter, C.; Jongedijk, C. E.; Kehl, C.; van Sebille, E. Global Modeled Sinking Characteristics of Biofouled Microplastic. J. Geophys. Res. Ocean. 2021, 1-15. https://doi.org/10.1029/2020jc017098.

(6) Matsuguma, Y.; Takada, H.; Kumata, H.; Kanke, H. Microplastics in Sediment Cores from Asia and Africa as Indicators of Temporal Trends in Plastic Pollution. Arch. Environ. Contam. Toxicol. 2017, 73 (2), 230-239. https://doi.org/10.1007/s00244-017-0414-9.

(7) Nakano, H.; Arakawa, H.; Tokai, T. Microplastics on the Sea Surface of the Semi-Closed Tokyo Bay. Mar. Pollut. Bull. 2021, 162 (October 2020).

https://doi.org/10.1016/j.marpolbul.2020.111887.

(8) Dibke, C.; Fischer, M.; Scholz-Böttcher, B. M. Microplastic Mass Concentrations and Distribution in German Bight Waters by Pyrolysis-Gas Chromatography-Mass Spectrometry/Thermochemolysis Reveal Potential Impact of Marine Coatings: Do Ships Leave Skid Marks? Environ. Sci. Technol. 2021, 55 (4), 2285-2295. https://doi.org/10.1021/acs.est.0c04522.

(9) Schernewski, G.; Radtke, H.; Hauk, R.; Baresel, C.; Olshammar, M.; Osinski, R.; Oberbeckmann, S. Transport and Behavior of Microplastics Emissions From Urban Sources in the Baltic Sea. Front. Environ. Sci. 2020, 8 (October), 1-17.

https://doi.org/10.3389/fenvs.2020.579361.

(10) Zarfl, C.; Matthies, M. Are Marine Plastic Particles Transport Vectors for Organic Pollutants to the Arctic? Mar. Pollut. Bull. 2010, 60 (10), 1810-1814. https://doi.org/10.1016/j.marpolbul.2010.05.026.

(11) Gouin, T.; Roche, N.; Lohmann, R.; Hodges, G. A Thermodynamic Approach for Assessing the Environmental Exposure of Chemicals Absorbed to Microplastic. Environ. Sci. Technol. 2011, 45 (4), 1466-1472. https://doi.org/10.1021/es1032025.

(12) Koelmans, A. A.; Bakir, A.; Burton, G. A.; Janssen, C. R. Microplastic as a Vector for Chemicals in the Aquatic Environment: Critical Review and Model-Supported Reinterpretation of Empirical Studies. Environ. Sci. Technol. 2016, 50 (7), 3315-3326. https://doi.org/10.1021/acs.est.5b06069.

(13) Yeo, B. G.; Takada, H.; Yamashita, R.; Okazaki, Y.; Uchida, K.; Tokai, T.; Tanaka, K.; Trenholm, N. PCBs and PBDEs in Microplastic Particles and Zooplankton in Open Water in the Pacific Ocean and around the Coast of Japan. Mar. Pollut. Bull. 2020, 151 (December 2019), 110806. https://doi.org/10.1016/j.marpolbul.2019.110806.

(14) Seymour, M. D. The Biodegradation of Particulate Organic Matter in Saltwater Media; 1977.

(15) Tanaka, K.; Takada, H.; Yamashita, R.; Mizukawa, K.; Fukuwaka, M. A.; Watanuki, Y. Facilitated Leaching of Additive-Derived PBDEs from Plastic by Seabirds' Stomach Oil and Accumulation in Tissues. Environ. Sci. Technol. 2015, 49 (19), 11799-11807. https://doi.org/10.1021/acs.est.5b01376.

(16) Tanaka, K.; Watanuki, Y.; Takada, H.; Ishizuka, M.; Yamashita, R.; Kazama, M.; Hiki, N.; Kashiwada, F.; Mizukawa, K.; Mizukawa, H.; Hyrenbach, D.; Hester, M.; Ikenaka, Y.; Nakayama, S. M. M. In Vivo Accumulation of Plastic-Derived Chemicals into Seabird Tissues. Curr. Biol. 2020, 30 (4), 723-728.e3. https://doi.org/10.1016/j.cub.2019.12.037. 
(17) Ruczyńska, W.; Szlinder-Richert, J.; Nermer, T. The Occurrence and Distribution of Nonylphenols and Nonylphenol Ethoxylates in Different Species of Fish. Environ. Sci. Process. Impacts 2020, 22 (4), 1057-1070. https://doi.org/10.1039/c9em00584f.

(18) Corrales, J.; Kristofco, L. A.; Baylor Steele, W.; Yates, B. S.; Breed, C. S.; Spencer Williams, E.; Brooks, B. W. Global Assessment of Bisphenol a in the Environment: Review and Analysis of Its Occurrence and Bioaccumulation. Dose-Response 2015, 13 (3). https://doi.org/10.1177/1559325815598308.

(19) Denghel, H.; Hiller, J.; Leibold, E.; Göen, T. Human Metabolism and Kinetics of the UV Absorber 2-(2H-Benzotriazol-2-YI)-4,6-Di-Tert-Pentylphenol (UV 328) after Oral Administration. Arch. Toxicol. 2021, 95 (8), 2677-2690. https://doi.org/10.1007/s00204-02103093-1.

(20) Canada. Screening Assessment Report on Phenol, 2-(2H-Benzotriazol-2-YI)-4,6-Bis(1,1Dimethylpropyl)- (BDTP); 2016.

(21) Andrade, H.; Glüge, J.; Herzke, D.; Ashta, N. M.; Nayagar, S. M.; Scheringer, M. Oceanic LongRange Transport of Organic Additives Present in Plastic Products: An Overview. Environ. Sci. Eur. 2021, 33 (1), 85. https://doi.org/10.1186/s12302-021-00522-x.

(22) Yamashita, R.; Hiki, N.; Kashiwada, F.; Takada, H.; Mizukawa, K.; Hardesty, B. D.; Roman, L.; Hyrenbach, D.; Ryan, P. G.; Dilley, B. J.; Munoz-Pérez, J. P.; Valle, C. A.; Pham, C. K.; Frias, J.; Nishizawa, B.; Takahashi, A.; Thiebot, J.-B.; Will, A.; Kokubun, N.; Watanabe, Y. Y.; Yamamoto, T.; Shiomi, K.; Shimabukuro, U.; Watanuki, Y. Plastic Additives and Legacy Persistent Organic Pollutants in the Preen Gland Oil of Seabirds Sampled across the Globe. Environ. Monit. Contam. Res. 2021, 1, 20210009. https://doi.org/10.5985/emcr.20210009.

(23) Turrell, W. R. Estimating a Regional Budget of Marine Plastic Litter in Order to Advise on Marine Management Measures. Mar. Pollut. Bull. 2020, 150 (November 2019), 110725. https://doi.org/10.1016/j.marpolbul.2019.110725.

(24) Onink, V.; Jongedijk, C. E.; Hoffman, M. J.; van Sebille, E.; Laufkötter, C. Global Simulations of Marine Plastic Transport Show Plastic Trapping in Coastal Zones. Environ. Res. Lett. 2021, 16 (6). https://doi.org/10.1088/1748-9326/abecbd.

(25) IPW. International Pettet Watch - Pollution Map on Google Earth http://www.pelletwatch.org/gmap/.

(26) Kooi, M.; Reisser, J.; Slat, B.; Ferrari, F. F.; Schmid, M. S.; Cunsolo, S.; Brambini, R.; Noble, K.; Sirks, L. A.; Linders, T. E. W.; Schoeneich-Argent, R. I.; Koelmans, A. A. The Effect of Particle Properties on the Depth Profile of Buoyant Plastics in the Ocean. Sci. Rep. 2016, 6 (September), 1-10. https://doi.org/10.1038/srep33882.

(27) Kowalski, N.; Reichardt, A. M.; Waniek, J. J. Sinking Rates of Microplastics and Potential Implications of Their Alteration by Physical, Biological, and Chemical Factors. Mar. Pollut. Bull. 2016, 109 (1), 310-319. https://doi.org/https://doi.org/10.1016/j.marpolbul.2016.05.064.

(28) Ryan, P. G. Does Size and Buoyancy Affect the Long-Distance Transport of Floating Debris? Environ. Res. Lett. 2015, 10 (8), 84019. https://doi.org/10.1088/1748-9326/10/8/084019.

(29) Lebreton, L. C. M.; Greer, S. D.; Borrero, J. C. Numerical Modelling of Floating Debris in the World's Oceans. Mar. Pollut. Bull. 2012, 64 (3), 653-661. https://doi.org/10.1016/j.marpolbul.2011.10.027. 
(30) HYCOM. HYCOM - Consortium for Data Assimilative Modeling https://www.hycom.org/.

(31) Meijer, L. J. J.; van Emmerik, T.; van der Ent, R.; Schmidt, C.; Lebreton, L. More than 1000 Rivers Account for $80 \%$ of Global Riverine Plastic Emissions into the Ocean. Sci. Adv. 2021, 7 (18), 1-14. https://doi.org/10.1126/sciadv.aaz5803.

(32) Kroodsma, D. A.; Mayorga, J.; Hochberg, T.; Miller, N. A.; Boerder, K.; Ferretti, F.; Wilson, A.; Bergman, B.; White, T. D.; Block, B. A.; Woods, P.; Sullivan, B.; Costello, C.; Worm, B. Tracking the Global Footprint of Fisheries. Science (80-. ). 2018, 359 (6378), 904-908. https://doi.org/10.1126/science.aao5646. 


\section{Appendix}

\section{Model results for Marion Island and Gough Island}

\section{Model setup}

The model used is described in more detail by Lebreton et al. (2012). ${ }^{29}$ In brief, floating plastics are represented by Lagrangian particles that are advected with sea surface currents. Ocean circulation data were sourced from HYCOM, ${ }^{30}$ a oceanic circulation modeling system forced by the US Navy's Operational Global Atmospheric Prediction System. The ocean circulation data covered the world from 2013 to 2019 (7-year simulation) at 1/12th degree resolution. Particles in the model were continuously released from representative source locations. Two source scenarios were investigated: 1) river sources based on the data of Meijer et al. (2021) ${ }^{31}$ and 2) fishing sources adapted from effort data mapped in Kroodsma et al. (2018). ${ }^{32}$

Particles that travelled to near Marion Island $(-46.88,37.75)$ and Gough Island $(-40.32,-9.93)$ in the global simulation were flagged and analyzed for distance and time traveled from source to the island of interest. The distances shown in the figures are the direct distances from source to island (and not the total length of the trajectories). Relative distributions are provided for total time traveled (Table 1), direct distance from source to island (Table 2), and total traveled distance (Table $3)$.

\section{Results for the river sources scenario}

As shown in Figure 1, no particles were observed near Marion Island. Particles predominantly from rivers of Brazil were observed near Gough Island.
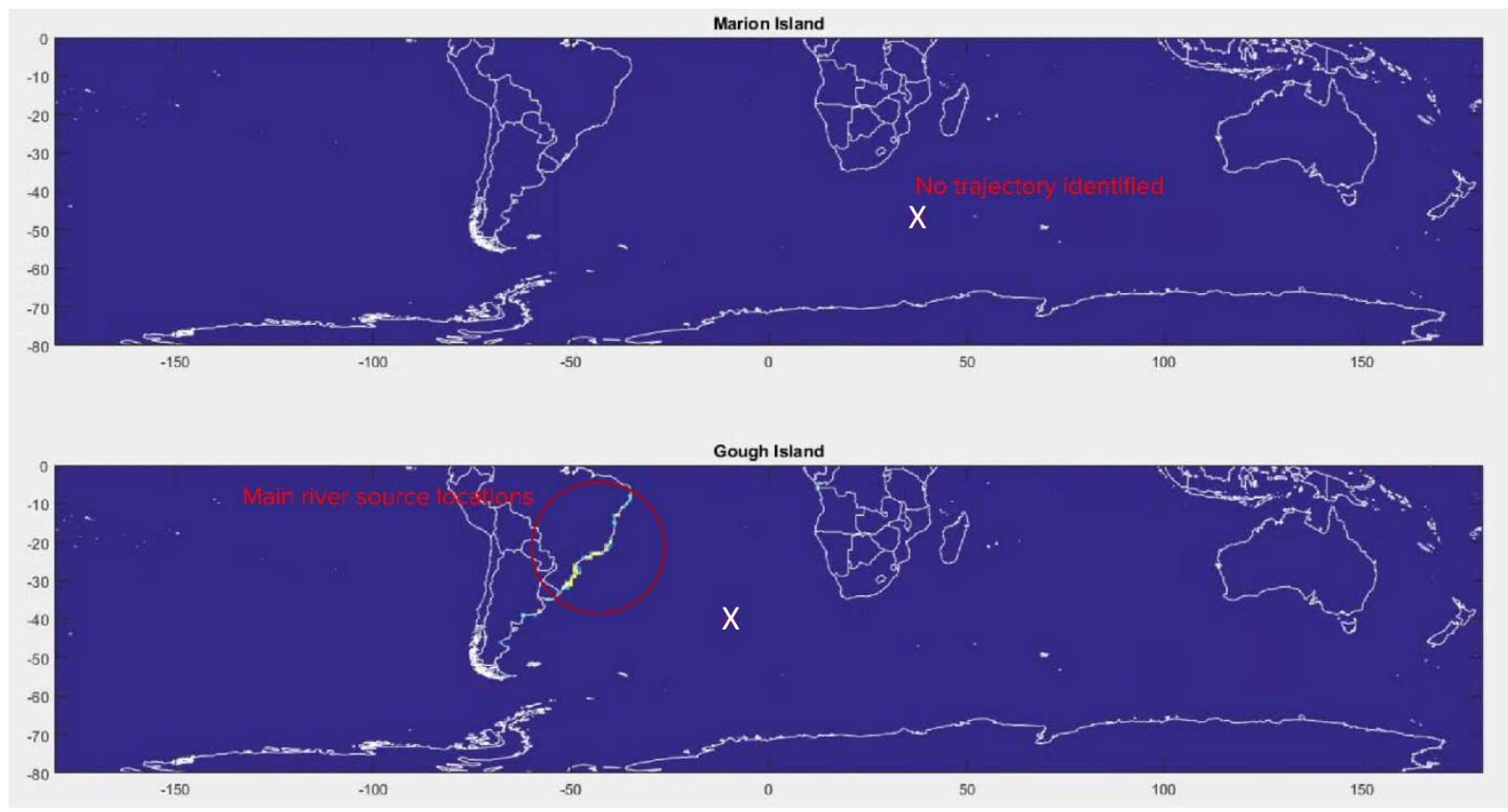

Figure 1: Maps with the river sources scenario for Marion and Gough Island (marked with an " $X$ ")

Figure 2 shows the distribution of the total travel time and distance from emission location to the respective island in the river sources scenario. 

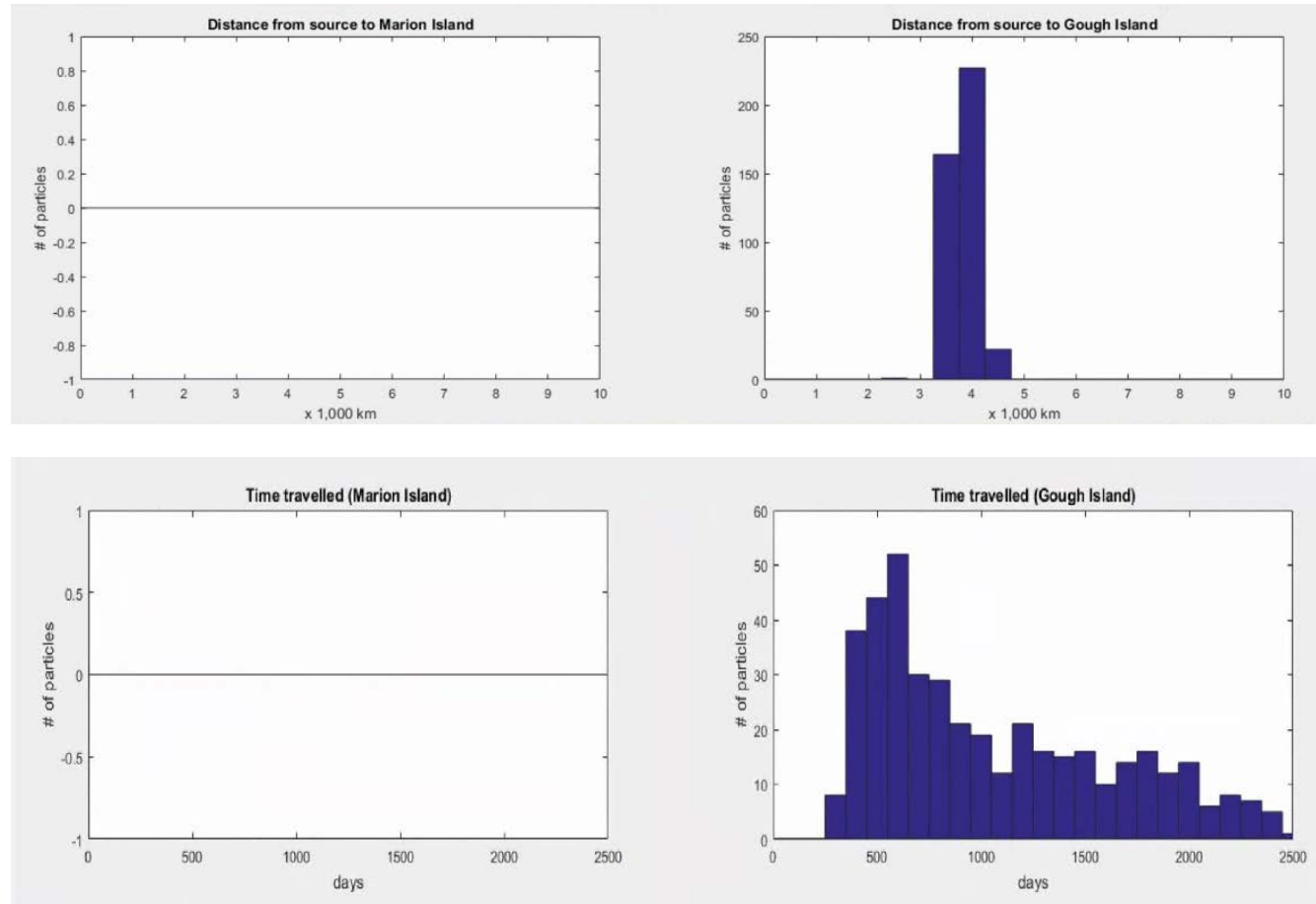

Figure 2: Distribution of total travel time and distance from emission location and respective island in the river sources scenario.

\section{Fishing sources scenario}

Figure 3 shows the locations of the sources from the fishing sources scenario. The few particles that were observed near Marion Island originated from southeast of the South American continent and fishing grounds near Antarctica. A small fraction of the particles came also from local fishing grounds, west of the Marion Island.
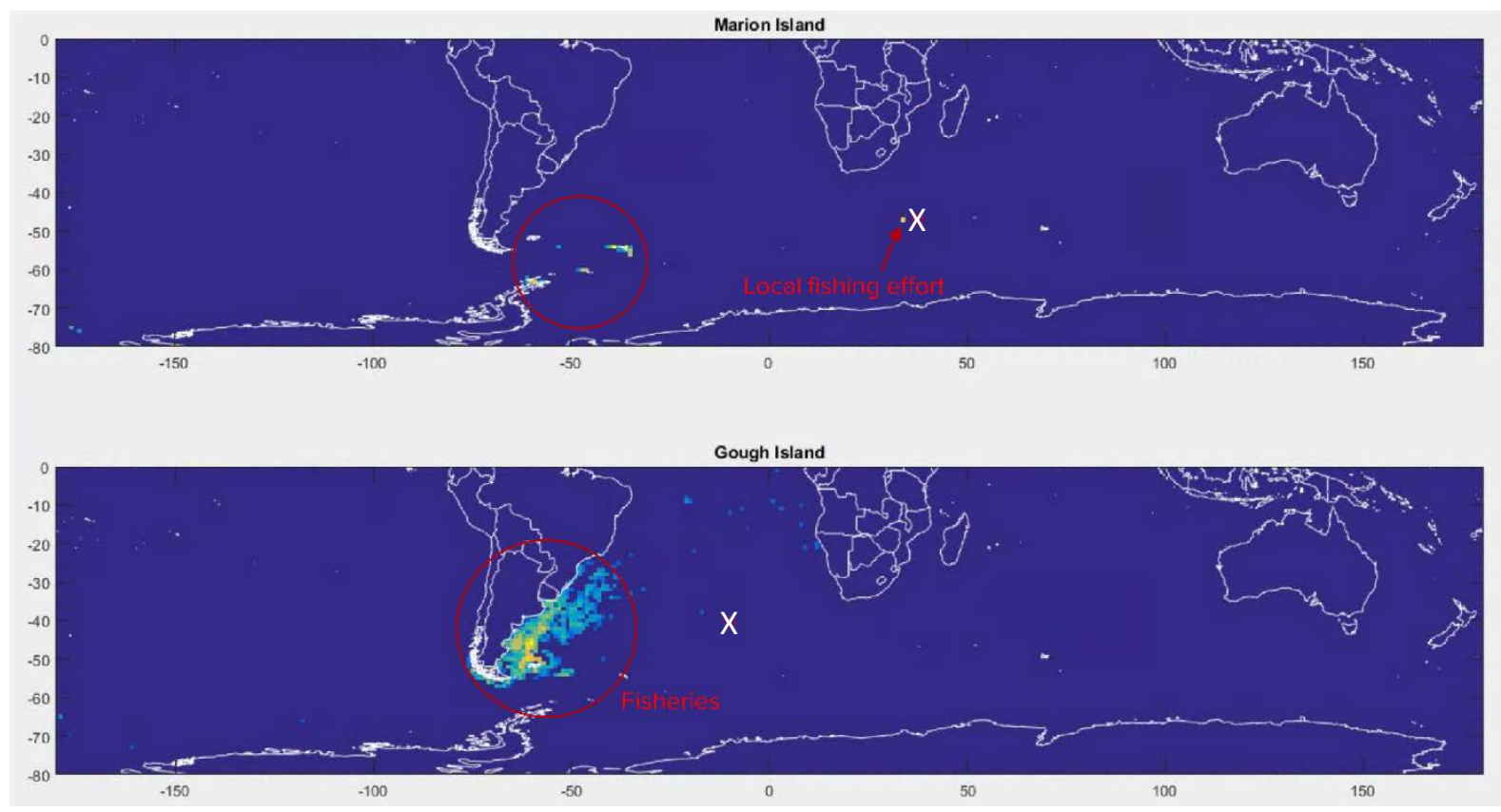

Figure 3: Maps with the fishing sources scenario for Marion and Gough Island (marked with an " $X$ ") 
Many more particles were observed near Gough Island, which mostly originated from fishing grounds offshore of Argentina. Figure 4 shows the distribution of total travel time and distance from emission location to the respective island in the fishing sources scenario.
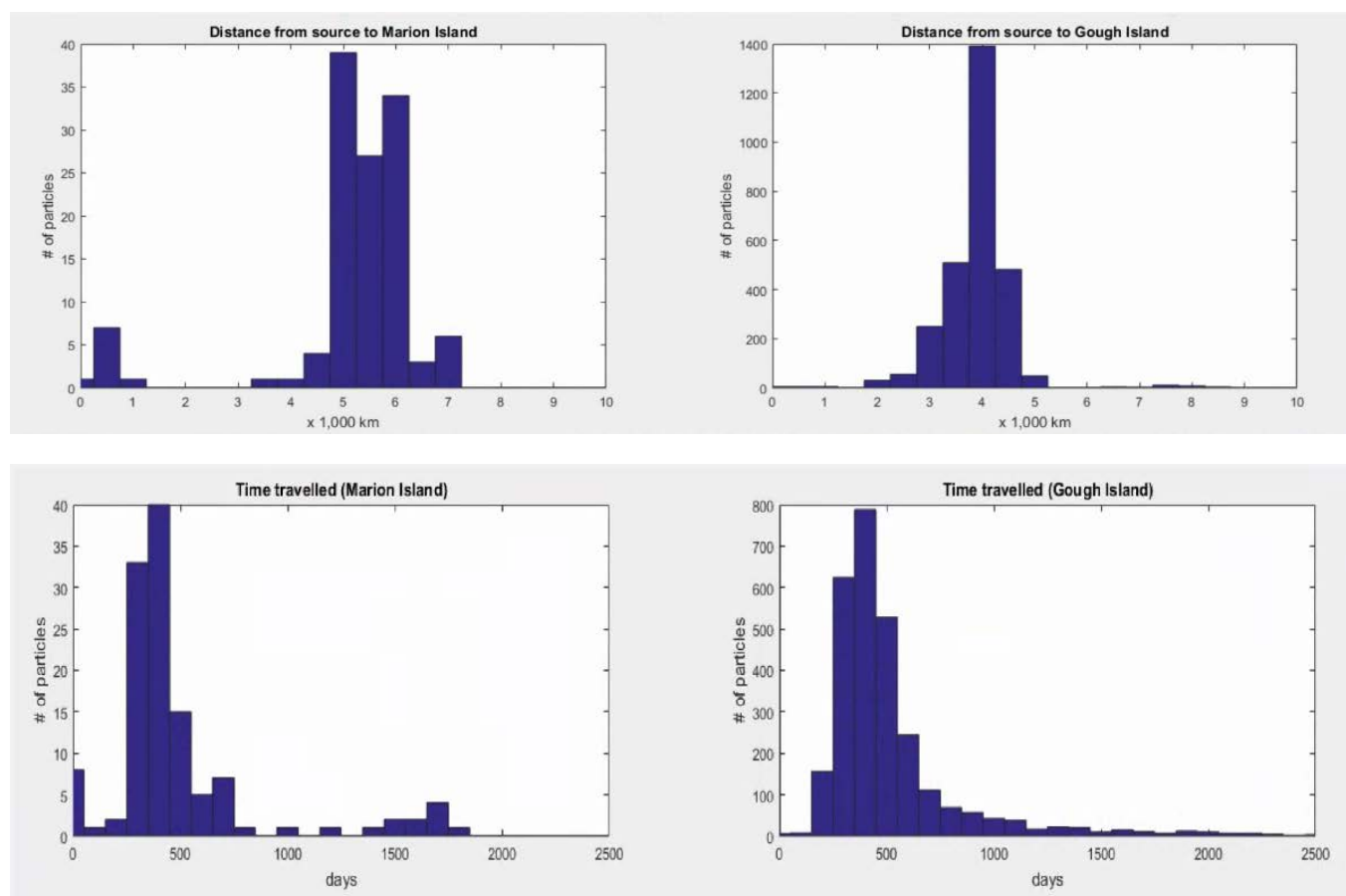

Figure 4: Distributions of total travel time and distance from emission location and respective island in the fishing sources scenario.

Table 1: Distribution of time traveled in days by model particles reaching Marion Island and Gough Island for two source scenarios (rivers and fishing sources). In the river sources scenario, no particles were detected traveling to Marion Island.

\section{FISHING SOURCES SCENARIO}

\begin{tabular}{r|rrrr}
\hline $\begin{array}{r}\text { \# days } \\
\text { (centered) }\end{array}$ & Marion Island & Gough Island & Marion Island & Gough Island \\
$\mathbf{0}$ & $6.5 \%$ & $0.2 \%$ & - & $0 \%$ \\
$\mathbf{1 0 0}$ & $0.8 \%$ & $0.3 \%$ & - & $0 \%$ \\
$\mathbf{2 0 0}$ & $1.6 \%$ & $5.5 \%$ & - & $0 \%$ \\
$\mathbf{3 0 0}$ & $26.6 \%$ & $22.2 \%$ & - & $2 \%$ \\
$\mathbf{4 0 0}$ & $32.3 \%$ & $28.0 \%$ & - & $9 \%$ \\
$\mathbf{5 0 0}$ & $12.1 \%$ & $18.7 \%$ & - & $11 \%$ \\
$\mathbf{6 0 0}$ & $4.0 \%$ & $8.7 \%$ & - & $13 \%$ \\
$\mathbf{7 0 0}$ & $5.6 \%$ & $3.9 \%$ & - & $7 \%$ \\
$\mathbf{8 0 0}$ & $0.8 \%$ & $2.4 \%$ & - & $7 \%$ \\
$\mathbf{9 0 0}$ & $0.0 \%$ & $2.0 \%$ & - & $5 \%$
\end{tabular}




\begin{tabular}{|c|c|c|c|c|}
\hline 1000 & $0.8 \%$ & $1.5 \%$ & - & $5 \%$ \\
\hline 1100 & $0.0 \%$ & $1.3 \%$ & - & $3 \%$ \\
\hline 1200 & $0.8 \%$ & $0.6 \%$ & - & $5 \%$ \\
\hline 1300 & $0.0 \%$ & $0.8 \%$ & - & $4 \%$ \\
\hline 1400 & $0.8 \%$ & $0.7 \%$ & - & $4 \%$ \\
\hline 1500 & $1.6 \%$ & $0.4 \%$ & - & $4 \%$ \\
\hline 1600 & $1.6 \%$ & $0.5 \%$ & - & $2 \%$ \\
\hline 1700 & $3.2 \%$ & $0.4 \%$ & - & $3 \%$ \\
\hline 1800 & $0.8 \%$ & $0.2 \%$ & - & $4 \%$ \\
\hline 1900 & $0.0 \%$ & $0.4 \%$ & - & $3 \%$ \\
\hline 2000 & $0.0 \%$ & $0.4 \%$ & - & $3 \%$ \\
\hline 2100 & $0.0 \%$ & $0.2 \%$ & - & $1 \%$ \\
\hline 2200 & $0.0 \%$ & $0.2 \%$ & - & $2 \%$ \\
\hline 2300 & $0.0 \%$ & $0.1 \%$ & - & $2 \%$ \\
\hline 2400 & $0.0 \%$ & $0.1 \%$ & - & $1 \%$ \\
\hline 2500 & $0.0 \%$ & $0.1 \%$ & - & $0 \%$ \\
\hline
\end{tabular}

Table 2: Distribution by direct distance in $\mathrm{km}$ from sources of model particles to Marion Island and Gough Island, for two source scenarios (rivers and fishing sources). In the river sources scenario, no particles were detected travelling to Marion Island.

\begin{tabular}{r|rrrr}
\multicolumn{2}{|c}{ FISHING SOURCE SCENARIO } & \multicolumn{2}{c}{ RIVER SOURCE SCENARIO } \\
\hline $\mathbf{k m}$ (centered) & Marion Island & Gough Island & Marion Island & Gough Island \\
$\mathbf{5 0 0}$ & $1 \%$ & $0 \%$ & - & $0 \%$ \\
$\mathbf{1 0 0 0}$ & $6 \%$ & $0 \%$ & - & $0 \%$ \\
$\mathbf{1 5 0 0}$ & $1 \%$ & $0 \%$ & - & $0 \%$ \\
$\mathbf{2 0 0 0}$ & $0 \%$ & $0 \%$ & - & $0 \%$ \\
$\mathbf{2 5 0 0}$ & $0 \%$ & $1 \%$ & - & $0 \%$ \\
$\mathbf{3 0 0 0}$ & $0 \%$ & $2 \%$ & - & $0 \%$ \\
$\mathbf{3 5 0 0}$ & $0 \%$ & $9 \%$ & - & $40 \%$ \\
$\mathbf{4 0 0 0}$ & $1 \%$ & $18 \%$ & - & $55 \%$ \\
$\mathbf{4 5 0 0}$ & $1 \%$ & $49 \%$ & - & $5 \%$ \\
$\mathbf{5 0 0 0}$ & $3 \%$ & $17 \%$ & - & $0 \%$ \\
$\mathbf{5 5 0 0}$ & $31 \%$ & $2 \%$ & - & $0 \%$ \\
$\mathbf{6 0 0 0}$ & $22 \%$ & $0 \%$ & - & $0 \%$ \\
$\mathbf{6 5 0 0}$ & $27 \%$ & $0 \%$ & - & $0 \%$ \\
$\mathbf{7 0 0 0}$ & $2 \%$ & $0 \%$ & - & $0 \%$ \\
$\mathbf{7 5 0 0}$ & $5 \%$ & $0 \%$ & - & $0 \%$ \\
$\mathbf{8 0 0 0}$ & $0 \%$ & $0 \%$ & - & $0 \%$ \\
$\mathbf{8 5 0 0}$ & $0 \%$ & $0 \%$ & - & $0 \%$ \\
$\mathbf{9 0 0 0}$ & $0 \%$ & $0 \%$ & - & $0 \%$ \\
$\mathbf{9 5 0 0}$ & $0 \%$ & $0 \%$ & - & $0 \%$ \\
$\mathbf{1 0 0 0 0}$ & $0 \%$ & $0 \%$ & - & $0 \%$ \\
& $0 \%$ & $0 \%$ & - & $0 \%$ \\
\hline
\end{tabular}


Table 3: Distribution of total distance traveled in $\mathrm{km}$ by model particles reaching Marion Island and Gough Island for two source scenarios (rivers and fishing sources). In the river sources scenario, no particles were detected traveling to Marion Island.

\begin{tabular}{|c|c|c|c|c|}
\hline & \multicolumn{2}{|c|}{ FISHING SOURCES SCENARIO } & \multicolumn{2}{|c|}{ RIVER SOURCES SCENARIO } \\
\hline km (centered) & Marion Island & Gough Island & Marion Island & Gough Island \\
\hline 0 & $6 \%$ & $0 \%$ & - & $0 \%$ \\
\hline 2000 & $1 \%$ & $0 \%$ & - & $0 \%$ \\
\hline 4000 & $0 \%$ & $1 \%$ & - & $0 \%$ \\
\hline 6000 & $6 \%$ & $6 \%$ & - & $0 \%$ \\
\hline 8000 & $43 \%$ & $18 \%$ & - & $1 \%$ \\
\hline 10000 & $25 \%$ & $24 \%$ & - & $13 \%$ \\
\hline 12000 & $6 \%$ & $17 \%$ & - & $18 \%$ \\
\hline 14000 & $1 \%$ & $11 \%$ & - & $21 \%$ \\
\hline 16000 & $2 \%$ & $6 \%$ & - & $16 \%$ \\
\hline 18000 & $1 \%$ & $4 \%$ & - & $13 \%$ \\
\hline 20000 & $2 \%$ & $3 \%$ & - & $8 \%$ \\
\hline 22000 & $1 \%$ & $2 \%$ & - & $4 \%$ \\
\hline 24000 & $3 \%$ & $2 \%$ & - & $2 \%$ \\
\hline 26000 & $2 \%$ & $1 \%$ & - & $1 \%$ \\
\hline 28000 & $1 \%$ & $1 \%$ & - & $1 \%$ \\
\hline 30000 & $0 \%$ & $1 \%$ & - & $0 \%$ \\
\hline 32000 & $0 \%$ & $1 \%$ & - & $0 \%$ \\
\hline 34000 & $0 \%$ & $1 \%$ & - & $0 \%$ \\
\hline 36000 & $0 \%$ & $0 \%$ & - & $0 \%$ \\
\hline 38000 & $0 \%$ & $0 \%$ & - & $0 \%$ \\
\hline 40000 & $0 \%$ & $0 \%$ & - & $0 \%$ \\
\hline 42000 & $0 \%$ & $0 \%$ & - & $0 \%$ \\
\hline 44000 & $0 \%$ & $0 \%$ & - & $0 \%$ \\
\hline 46000 & $0 \%$ & $0 \%$ & - & $0 \%$ \\
\hline 48000 & $0 \%$ & $0 \%$ & - & $0 \%$ \\
\hline 50000 & $0 \%$ & $0 \%$ & - & $0 \%$ \\
\hline
\end{tabular}

